\title{
CHALLENGES FACED IN IMPLEMENTING FREE PRIMARY EDUCATION FOR PASTORALISTS IN KENYA
}

\author{
David Serem, Richard Kipngeno Ronoh \\ Narok University College, Narok, Kenya \\ E-mail: tdkserem@yahoo.com, ronohrichard@gmail.com
}

\begin{abstract}
Governments in Sub-Saharan Africa allocate between $5 \%$ and $25 \%$ of public expenditure budgets to education ministries, because education is seen, correctly, as a major contributor to human welfare, social and economic development (World Bank, 2005). It is clear that these large expenditures are sub-optimal and provide less than the expected return. This situation has been felt more acutely with the introduction of free primary education (FPE). Despite the high enrolment in FPE in urban areas, the response from pastoral communities has been rather lukewarm.The general objective of the study was to investigate the challenges faced in implementing Free Primary Education policy among pastoralists in Kenya. Consequently, the rationale of this study lies in need to evaluate the impact of an educational policy and find out how its implementation responds to challenges in provision of access to Primary Schooling. The study adopted ethnographic research design that utilised purposive sampling technique and saturation procedure to select a total of 170 respondents that included head teachers, teachers, parents, school dropouts, educational managers, community leaders, and Non Governmental Organizations. Purposive sampling was used to select individuals, groups and organizations that would provide insight into the study. Data was collected using focus group interviews, structured and unstructured interviews, observation, and document analysis. Subsequently, data was collected by use of questionnaire that was sent to headteachers and education officials and was used only to validate the qualitative data. The collected data was coded, analyzed, described and summarized in order to generate themes on educational policy and practice. The study identified various challenges such as: inadequate funding; poor infrastructure; limited awareness towards education; limited community support; insecurity and cattle rustling and lifestyle of pastoralists that impedes the government's efforts to attain FPE. These challenges threatened the implementation of FPE for pastoralists and further illustrate the complex and messy process of policy implementation in education sector.
\end{abstract}

Key words: free primary education (FPE), policy implementation, pastoral communities, challenges.

\section{Introduction}

The target of Education for All by 2015 will not be met unless efforts are made to improve access for marginalised, hard-to-reach children, including nomadic and pastoralist groups, (Sheila, 2006).

Many countries have made a commitment towards achieving Education for All, but the high cost of implementing UPE has made progress towards this goal slow, especially among pastoralist communities, who live in harsh environments and who generally have low enrolment figures. Pastoralism continues to adapt new coping strategies against the numerous challenges facing the educationally disadvantaged communities. Any attempt to change or divert them from their cherished culture and resources would likely be met by resistance.

In all the countries, Roy and Edwina (2005) reports that the rate of primary school enrolment for children in nomadic communities is significantly below the national average. In 
Nigeria, the nomads' major constraints to participating in existing basic education programs Volume 41,2012 were found to result from constant movements in search of water and pasture (Otive, 2006). There has been attempt by governments and NGOs to examine the critical role of children in the pastoralists' production systems in order to understand what makes parents and guardians reluctant to release them to participate in informal schooling.

The introduction of free primary education (FPE) in Kenya in 2003 had a profound impact on the education sector. The sudden influx of pupils placed huge strains on the resource infrastructure of primary schools all over the country. However, the unique circumstances of primary schools in areas where pastoralism is the predominant mode of production present different and more severe challenges to implementing free primary education. Although many studies have been conducted on various aspects of pastoralism as a way of life, including its interactions with and effects on education, there have been comparatively few studies on how the introduction of FPE has been carried out in pastoralist communities.

This paper is motivated by the need to correct regional imbalances and injustices in view of a workable commitment to remove barriers to access in education through policy interventions. The government's commitment to fulfil EFA goals by 2015 is being challenged by a slow progress and the low enrolment rates among marginalized groups. Therefore this paper identifies challenges to FPE implementation and offer recommendations to overcome them.

\section{Statement of the Problem}

Educational programs often underscore the need to enhance access to education among pastoral communities but most fall short of specifically responding to barriers and challenges. Harsh and isolated environments would put pressure on competent teachers to seek for transfers. There are apparent challenges that keep the statistics of enrolment rates so low among pastoralists as compared to other regions in the country. The complex relationship between pastoral communities and their socio- economic background casts more doubts as to how the local people are involved in policy process of improving access to primary schooling. This problem is compounded by the challenges generally faced in implementing Free Primary Education, Kipkoech and Kyalo (2010).

\section{Evolution of Education Policy in Kenya}

Educational policy has evolved over time with focus on key areas such as the following: Education and development; equity considerations; quality of education; structure, administration and management of education; curriculum; cost and financing of education; planning techniques and approaches; information systems; monitoring and evaluation. Education policy making, while considering pastoralists, has always been to focus on regional balance and equity considerations.

After independence, the government has addressed educational issues through commissions, committees and taskforces. Ominde Report (1964) sought to reform education system that was colonial oriented to make it more responsive to the needs of the country. By then, the needs of the pastoralist communities had not received attention in the national arena as it is presently.

Consequently, the Report of the Presidential Working Party on Education and Manpower Training for the Next Decade and Beyond (The Kamunge Report, 1988) focused on improving education financing, quality and relevance. The report provided opportunity for creation of relevant education to all groups of people but may have done little in paving way for specific education system relevant to specific groups like pastoralist communities. 


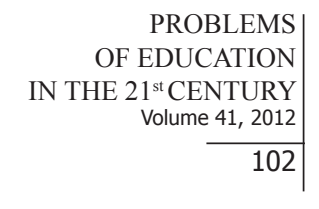

In the recent past, focus has been on the attainment of EFA by 2015 and more particularly the Universal Primary Education (UPE). However, as much as many policy initiatives have targeted access, retention, equity, quality and relevance of education system, the success entirely depends on whether interventions carried out response to challenges.

Historically education policies have tended to neglect pastoralist areas. Education participation and attainment in pastoralists' areas has been low in relation to other areas, (Kratli and Dyer, 2009). The colonial government was not interested in pastoralists' areas which led to low rates of formal education; there were also low missionary activities in these areas. Even after independence little was done to rid disparities and marginalization of pastoralists communities. The status quo is at the moment putting the government on toes in its attempt to formulate a relevant policy for the marginalized groups, an exercise which is not easy even with the creation of Ministry for the ASAL regions and marginalized groups. This is because, coming up with a relevant policy, requires political good will and interactions of state and civil society. There is need to examine the histories and practices that shapes and guide the problems in successful policy implementation. The process must undertake the difficult task of finding out how policy should encourage greater inclusion of otherwise excluded regions and groups.

Constant review to educational policy for the nomads have been necessitated by the fact the existing system of formal education is designed for sedentary groups, implying that the pastoral groups would have to settle down if their children would have to go to school. According to Dall as cited in Roy and Edwina (2005), "educational programs for nomads have failed primarily because decision makers have sought to use education as a tool for transforming nomadic populations into sedentary ones". This may make parents see no value in education which appears to be in immediate conflict with their lifestyles and socio- economic activities.

Based on the backdrop of dynamic evolution of pastoral lifestyles in response to constant environmental changes, there is need for review of policy from time to time in order to come up with interventions. The characteristics inherent in a particular community may have direct or indirect influence on the performance of educational policy. According to Wadi (1995), policy analysis should consider a number of aspects within the context of social, political, economic, demographic, and cultural issues which are likely to affect the decision making and even implementation processes of educational policies.

In an attempt to formulate educational policy for the Pastoral community, it is important to understand the environmental and economic challenges they go through. According to Mohamoud (1993), "The world economy is changing drastically, and pastoral nomads everywhere must feel the impact. They have been at the mercy of shifting commodity prices, tariff regulation, and trading patterns over which they have little or no control".

Cristian (2006) states that the decisive feature of educational policies and reform of the 1990s is the political consensus, shared by government and opposition, about education's strategic importance for economic growth, social integration, and democracy, and on the necessary fundamental policies. However, within the Kenyan political context and divergent party manifestos, political conflicts and misunderstanding tends to complicate coming up of a common policy. Educational reform becomes complicated because it involves and affects a large number of interests groups.

According to Institute of Development Studies (2006), policy processes include some perspectives at the expense of others and it is the perspectives of the poor and marginalized that are often excluded. Just as important, policy requires an understanding of more complex underlying practices of policy framing - the way boundaries are drawn around problems, how policy problems are defined, and what is included and excluded. In essence, policy processes should take into account how problems and policy solutions come to be defined, by whom, and to whom.

There are elements in policy making and of which, according to this discussion, must 
be clearly articulated in order to improve the process. Some of these elements are: Agents of change or resistance to change; social, political and institutional influences; donor and external influences; innovations and knowledge; policy drivers and communication and dissemination.

Policies do face contradictory responses based on different institutions and their individual views. Recipients may be divided along conservatism and radicalism even within the same institution. Furthermore, diversity of influences affecting policy development ranges from politics to donor and external influences. Policy makers sometimes find it difficult to reconcile the demands by donors and the educational needs of the people.

\section{Methodology of Research}

The theoretical perspective that underpins the methodology and methods of data collection is drawn largely from qualitative literature for this study. The study majorly adopted qualitative research approach in data analysis. A qualitative fieldwork was to analyze educational practice in the context of access and policy implications. Educational research is essentially concerned with exploring and understanding social phenomena which are educational in nature, mainly pertaining to formalized and/or spontaneously occurring social, cultural, psychological processes which could be termed as education, (Dash,1993).

The culture of pastoralists' communities is complicated and surrounded by myths and theories held by people not from the region. As the most suitable methodology of gaining indepth and breadth of the internality of the Turkana community, qualitative approach helped to develop grounded theory on access to Primary Schooling. It was important for the study to develop empathic understanding on the process by which pastoralists interact with the policies geared towards promoting access to education among them and attempt to interpret attitudes and meanings they attach to the programs.

According to Creswell (2002), qualitative researchers are concern primarily with the process and in meanings of how people make sense of their experiences. There was, therefore, need to utilize qualitative research methods to explore where and why policy and practice are at odds towards achieving full access to education.

Most educational studies for Turkana pastoral community gives quantitative data analysis whose validity should be checked by qualitative research that "permits research to go beyond the statistical results usually reported in quantitative research" (Mugenda and Mugenda, 1999:155). In that respect, it deemed necessary for the study to utilize qualitative methods in order to try to understand activities and provisions in the FPE as understood by the pastoralists, local leadership and other stakeholders.

Ethnographic study research design was used in this study where data was collected using focus groups, structured and unstructured interviews and observation field notes. According to Oreglia (2008), ethnography is a "social discipline that seeks to understand a community or a specific issue within it by gathering first-hand information from informants, mostly through interviews, observation and the collection of artifacts". It was necessary for the study to conduct informal conversations and in- depth interviews in order to understand the context within which primary schooling takes place among pastoralists in Turkana South District. There study made an elaborate attempt to understand the social cultural context through the interpretations, experiences and perceptions and meanings given by those living within this specific context.

According to Davies (2007), Ethnography is "a research process based on fieldwork using a variety of (mainly qualitative) research techniques". The author emphasizes the need for engagement in the lives of those being studied over an extended period of time in a manner that is interpretive and neither subjective nor objective. The design was, therefore, chosen as a qualitative research method for describing, analyzing, and interpreting cultural organizations shared patterns of behavior and beliefs as regard to primary schooling. 


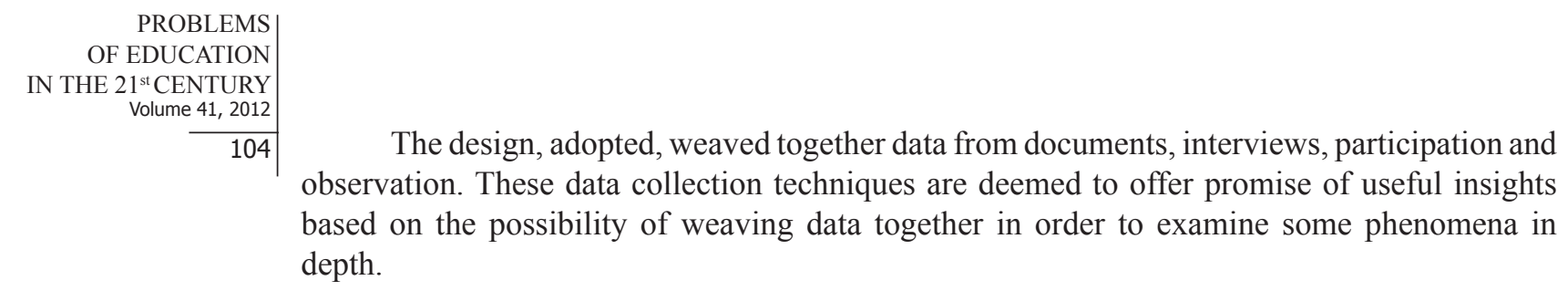

Sample Size and Sampling Procedures

A study that uses purposive or judgment sample may require developing a framework of the variables that might influence an individual's contribution. There is need therefore for intellectual strategy where subjects are stratified according to perceived public attitudes or beliefs, (Marshall, 1996).

Sandelowski (1995) holds the view that determining adequate sample size in qualitative research is ultimately a matter of judgment in evaluating the quality of the information collected against the purposeful sampling strategy employed and the research product intended.

The study considered heterogeneity sampling which according to Trochim (2006) the procedure would help in getting broad spectrum of ideas if a broad and diverse range of participants are sampled. The number of participants in each of the heterogeneous groups considered largely depended on saturation as utilized in qualitative studies. Mason (2010) reiterates that determining the sample size in the majority of qualitative studies should generally follow the concept of saturation, when the collection of new data does not shed any further light on the issue under investigation.

Primary data was therefore collected from a total sample of 170 respondents. The sample constitutes the following: 10 head teachers; 5 education officials; 20 teachers; 20 community leaders; 20 parents; 25 community members; 5 NGOs representatives; 25 school drop outs and five focus groups with an average of 8 members.

The qualitative study primary aim at providing illumination and understanding of the social, cultural and economic issues surrounding the state of FPE program, it was necessary to adopt purposive yet Judgmental sampling in order to have access to informants considered to be having more in-depth information than others. According to Marshall (1996), qualitative investigation requires more intellectual strategy rather than the simple demographic stratification where the researcher should actively select the most productive sample to answer research question. It deemed necessary to the study to sample subjects who like teachers, educational officials and local leaders for their special expertise and experience. During the sampling process, efforts were made to ensure that selection of participants capture important stake holders of FPE program in Turkana South District.

Traditionally, the ethnographer focuses attention on a community, selecting knowledgeable informants who know well the activities of the community, (Wikipedia, n.d). These informants are asked to identify other informants who represent the community, often using chain sampling.

According to Merriam (1998:61) purposive sampling emphasizes on a criterion-based selection of information rich cases from which a researcher can discover, understand and gain more insight on issues crucial for the study. The sampling process, therefore, selected individuals, groups and organizations that would provide insight into the phenomena under study.

\section{Data Collection Instruments and Procedures}

The study adopted methods of data collection that tend to be open- ended with less structured protocols. Data collection relied heavily on interactive interviews that took a great deal of time and all through the process, recording was done systematically by making field 
notes, sketches and photographs as it befitted the qualitative study. The methods used in the Volume 41,2012 study were: in- depth interviews; focus groups; document analysis and use of observation schedules. However, it deemed necessary to administer a questionnaire on education officials and teachers for validating qualitative data.

The researcher conducted debates on policy implications and factors affecting access to Primary Schooling. The researcher trained one research assistant beforehand and kept close supervision of his exercises with a view to offer control, advice and assistance in challenging situations. Data collection schedules were checked for completeness, errors and inconsistencies during the data collection phase and any discrepancies were resolved. As part of quality control procedures, it was necessary to eliminate responses that were not required and at the same time look for new insights from respondents during the period of the study.

\section{Data Analysis and Presentation}

The observation, interview and focus groups schedules were checked for completeness and consistency of information at the end of every field data collection day and before storage. They were then coded, edited and summarized to facilitate answering the research objectives and questions. This was done using both descriptive statistics.

The study adopted a framework analysis of data as prescribed by Lacey and Luff (2007). The approach is inductive and allows for a priori as well as emergent studies as data collection and data analysis occur concurrently. According to lacy (ibid), key stages of framework analysis includes the following: familiarization; identifying a thematic framework; indexing of data; charting; mapping and interpretation. The descriptive analysis, including frequencies, percentages, tables and cross-tabulations, was used to summarize and organize data and to systematically describe common themes, concerns and opinions of the participants. The study attempted to seek relationships between such themes and arrived at implications for FPE policy.

Generally, data analysis involved coding and developing categories based on research objectives. However, the study also undertook careful examination of unsolicited explanations with a view to develop extra relevant insights to the study and avoid bias in interpretation. Research assistants critically examined data analysis for possible errors and untrue representation of the target population.

\section{Results of Research}

\section{Challenges Faced in Implementing Free Primary Education for Pastoralists}

It was important for the researcher to seek this information to ascertain the general challenges facing the implementation of free primary education for pastoralists to provide the stake holders a deep understanding of the challenges. Figure 1 below presents the responses of the participants regarding the suggested challenges faced in the implementation of free primary education for pastoralists. 


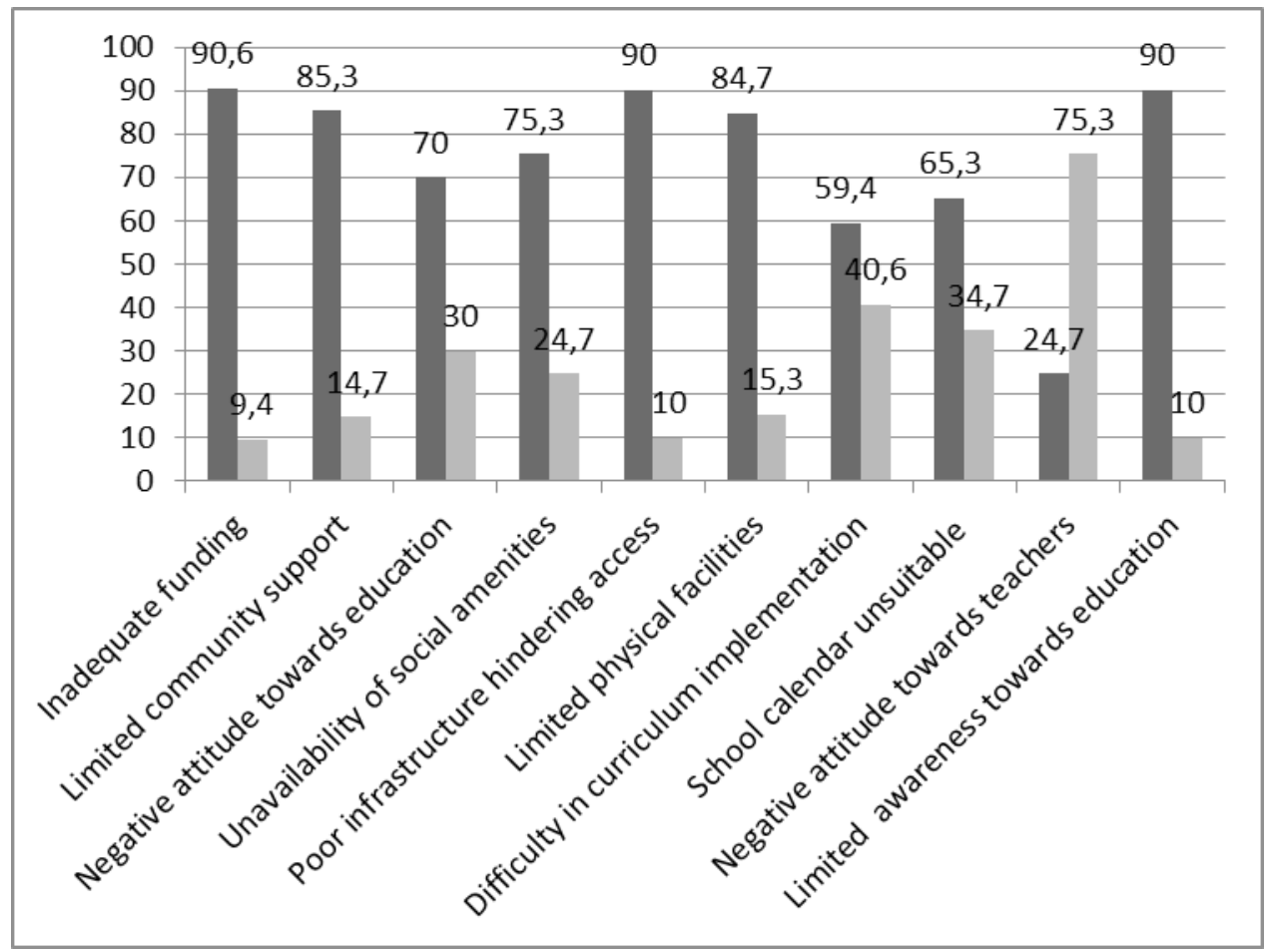

Figure 1: Challenges faced in implementation of Free Primary Education.

As shown in the figure above, $90.6 \%$ of the participants agreed that inadequate funding posed a challenge in the implementation of FPE. As regard to other challenges in implementing FPE for pastoralists, the following findings were reflected: $85.3 \%$ felt that there was limited community support; $70 \%$ cited negative attitude towards education; $75.3 \%$ concurred that there was lack of social amenities; $90 \%$ were of the view that poor infrastructure hindered access to schools; $84.7 \%$ noted that there were limited physical facilities; $59.4 \%$ agreed that there were difficulties in the implementation of the curriculum; $65.3 \%$ noted that the school calendar was not suitable for pastoralist mode of living; $90 \%$ of the participants cited limited community awareness towards education as a major challenge.

Further to the shared views on challenges, some zones experienced banditry and cattle rustling. Schools in Lokori division and Kainuk division complained of frequent attacks by neighboring hostile communities and the fear caused had kept many children out of school. Some of the primary schools that were affected by such raids were: Kakong; Nakwamoru; Kaputir; Kainuk Mixed; Kainuk Girls; Kalemungorok; and Korinyang. Banditry and cattle raiding have been responsible for difficulties faced by teachers, parents and school children of pastoralist community in accessing free primary education in Turkana South District.

These findings were in tandem with reports by TDDP, 2002- 2008: 22 which states that during these raids "the district suffers a lot, in terms of loss of life, loss of property, displacement of families, destruction of infrastructure e.g. schools, health and water facilities and disruption of education and farming. In the past, pastoralists in East Africa have engaged in cattle rustling and aggressive confrontation as a strategy for survival, (Markakis, 1999).

On negative attitude towards education, the study found out that the major challenge lies in inadequate community awareness on how primary education builds and support their social and economic coping strategies in the region. The pastoral community, to a large extent, lacks ownership of FPE, a situation which impedes efforts to have every child go to school. 


\section{School Drop-outs}

PROBLEMS

OF EDUCATION

IN THE $21^{\text {st }}$ CENTURY

Volume 41, 2012

107

The FPE in Turkana South District is faced with the myriad of challenges that cause increased dropout rates. The study found out that most primary school pupils dropout of school due to the strong influence of socio- cultural factors such as early marriages and domestic responsibilities. While statistics in other district show decreased dropout rates, the lifestyle of pastoralists in the District impedes the government's efforts to attain universal primary education for all. Figure 2 further illustrates the findings.

\begin{tabular}{|c|c|c|c|c|c|}
\hline \multicolumn{6}{|l|}{25} \\
\hline \multicolumn{6}{|l|}{$\begin{array}{ll}\mathbf{r} & 20 \\
\text { o } & \end{array}$} \\
\hline \multicolumn{6}{|l|}{ o 10} \\
\hline \multicolumn{6}{|l|}{ t } \\
\hline $\begin{array}{l}0 \\
r \quad\end{array}$ & 2003 & 2004 & 2005 & 2006 & 2007 \\
\hline durkana & 8,4 & 22 & 0,5 & 12,2 & 18,2 \\
\hline tjara & 6,5 & 18,7 & 5,9 & 18,6 & 2,2 \\
\hline éarissa & 2,1 & 17,3 & 7,2 & 7,4 & 3,9 \\
\hline \$siolo & 1,2 & 9,8 & 14,2 & 12,3 & 0,4 \\
\hline Suba & 2,8 & 9,1 & 9,3 & 6,5 & 0,8 \\
\hline Kajiado & 1,6 & 2,8 & 9,7 & 8,7 & 0,8 \\
\hline Kitui & 1,4 & 3,6 & 4,5 & 4,2 & 0,3 \\
\hline Koibatek & 1,1 & 2,9 & 2,8 & 6,3 & 0,8 \\
\hline Baringo & 1,6 & 3,3 & 0,4 & 6,8 & 0,8 \\
\hline
\end{tabular}

Source: MOE (2009).

Figure 2: Drop-out Rates of Selected Districts between 2003- 2007.

Even though $55.9 \%$ of respondents were not convinced that dropout rates have affected implementation of FPE policy, other findings on the ground seem to be in tandem with the statistics at the Ministry of education that dropout rate in the region is one of the highest (Figure 2). According to report by MOE (2009), dropout rate in Turkana is one of the highest and did not improve as compared to most districts in the country. In 2007, except for Turkana with dropout rate of 18.2, most districts seemed to have had positive impact from interventions by the government to curb dropout in schools. The same report indicate that some districts like Makueni, Muranga and Taita Taveta have had all time low Dropout rates in primary schools, MOE (2009). 


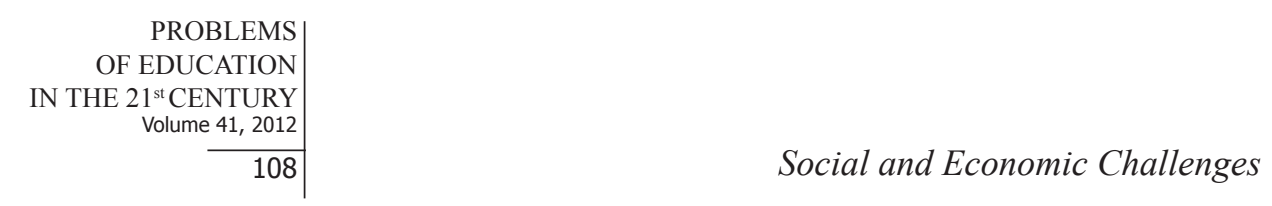

All the participants noted that the vastness and remoteness of the area where the Turkana pastoralists live make it difficult to access primary education. This, they noted is made worse by the poor infrastructure. There is lack of proper roads and means of transport to cover all the areas occupied. The long distance that pupils are required to cover to schools exposes them to insecurity. Some of them therefore opt out of the schools.

Over eighty percent of the educational officials and teachers decry the poor school conditions. They reported that lack of physical facilities has led to congestion in the available classrooms. This in turn has compromised the standards of education. The community leaders who feel that by only catering for tuition, the government of Kenya has not done enough to address the poor state of some schools also lamented lack of such facilities.

To this end, all the community leaders interviewed claimed that Free Primary Education is still not affordable since the parent has to cater for the most vital components of education such as provision of school uniform and provision of infrastructure including physical facilities. They however agreed that NGOs have come along way in trying to address some of these issues. Some of the teachers interviewed expressed concern over some sponsors preferring their own to run schools. They gave the example of the Catholic Church whereby Catholic teachers must run most of the schools sponsored by the Church.

Ninety five percent of the participants identified Poverty as a key challenge to educational policy makers in this region. They expressed appreciation for the effort NGOs are making. However, they noted that NGOs are not meeting all the needs of the community such as uniforms and food. One community leader even suggested that most of the programs implemented by the government and the NGOs did not benefit the Turkana pastoralist community because the personnel involved are 'alien' to them. They recommended school feeding program be more support and resources and that local people should be involved in every implementation stage.

\section{Conclusions}

The study identified following challenges as the main threats to the implementation of FPE for pastoralists: Inadequate funding; poor infrastructure; limited awareness towards education; limited community support; insecurity and cattle rustling; limited physical facilities; unavailability of social amenities; negative attitude towards education; social calendar not suitable for the pastoralist mode of living and difficulty in curriculum implementation. This is reaffirmed by an assertion by Markakis (1999) that in the past, pastoralists in East Africa have engaged in cattle rustling and aggressive confrontation as a strategy for survival.

Despite its progress, FPE programme faces several challenges that has hampered the smooth implementation was clearly articulated by all the respondents as follows: shortage of teachers; lack of consultation with teachers; parents and communities; delay in disbursement of funds; lack of regular communication to sensitize the various stakeholders on their roles; insecurity and cattle rustling. There was general misconception about the meaning of 'Free Education' with parents taking the view that they were no longer required to participate in school activities. The political leaders were also sending conflicting signals to the parents and communities as they point out that fund drives or voluntary contributions were not acceptable.

\section{Recommendations}

In view of the above challenges, various respondents recommended interventions through change and improvement of policy. It was established from the study through the openended questionnaire that it is very difficult for a teacher who has no training in accounting 
matters to effectively manage FPE funds. Therefore the government should consider employing accountants in primary schools to manage the funds, as it happens in secondary schools.

The money given for FPE per pupil per year for teaching and reading materials as well as for other expenses is not enough. It is imperative, therefore, for the government to source for more funds (from both local and external resources) in order to increase the allocation per pupil.

The ministry of education should use the mass and the provincial administration to popularize FPE among the pastoralist communities and inform parents and communities of what they are expected to do to make it succeed. The government should address the longterm sustainability of the FPE program, as well issues of quality assurance and maintenance of standards.

There is need for the government to differentiate between urban schools and rural schools in the allocation of funds, instead of awarding equal amounts to schools solely on the basis of enrolment. Despite the Kenyan government's heavy investment in education, enrolment at various levels of education is characterized by regional and gender disparities and declining gross enrolment ratios, (Alwiya and Susanne, 2004).

The ministry of education auditors and inspectors should induct school committees and head teachers on a continuous basis. The government should clarify funding sources, define role of various stakeholders, and provide a framework for instilling discipline and conducting assessments. The importance of examining the roles of various stakeholders is strengthened by the vie held by Cristian (2006) that leadership groups responsible for educational reform must be "cohesive and without conflict" because they are in strategic positions for effecting policy change.

The government should consider employing more teachers to ease the shortage, it could also consider engaging contract teachers, who would be cheaper to maintain. The study recommends that part ort of the constituency development funds be used to put up classrooms and toilets or rehabilitate facilities in schools to provide pupils with conducive learning environment for the pastoralists' children. Parents and Community members should be encouraged to raise funds through sale of their animals to provide buildings and other physical facilities to schools.

Respondents stressed the need for additional funds for needy schools to enable them put up physical facilities since parents no longer pay for building fees. It was recommended that parents and communities members should be made aware that it is their obligation to ensure that all children are taken to schools.

Finally, the government should undertake serious and effective strategies for conflict resolutions to mitigate the problem of insecurity and cattle rustling that scare away teachers and many would be investors in the region. As earlier stated, Manish (1997) explains that most educational policies fail to recognize the powerful, informal dynamic learning environments that exist or are continually emerging. In practice, policies require implicit adjustments in the direction of the links between education and society, (Abby R., 2003).

This paper has comprehensively addressed the challenges in implementing free primary education for pastoralists, and recommended strategies that can be used to enhance FPE in marginal areas. Although it was only briefly mentioned in this paper, the issue of funding is crucial to the success of FPE, not only in pastoralist communities but also throughout the country. Therefore, this paper concludes that increased funding to the education sector, and FPE in particular, can alleviate the challenges faced by pastoral communities in the implementation of FPE 


\section{PROBLEMS OF EDUCATION IN THE $21^{\text {st }}$ CENTURY Volume 41,2012 \\ References}

Abby, R. (2003). The Introduction of free primary education in Sub-saharan Africa. UNESCO, 2004/ $E D / E F A / M R T / P I / 62$. Lastly checked on $23^{\text {rd }}$ May, 2010 from unesdoc.unesco.org/images/0014/ 001469/146914e.pdf

Alwiya, A., Susanne, S. (2004). Ethnic inequalities in education in Kenya. International Education Journal, 5 (2), Retrieved from http://iej.cjb.net

Creswell, J. W. (2002). Research design: Qualitative, quantitative and mixed methods approaches ( $2^{\text {nd }}$ ed.). Thousand Oaks, Sage Publications.

Cristian, C. (2006). Policy formation and implementation in secondary education reform: The case of Chile at the turn of the century. Washington, The World Bank. Retrieved from www.worldbank. org/education

Davies, C. A. (2007). Reflexive ethnography: A guide to researching ourselves and others. Routledge, Charlotte Aull Davies.

Dash, N. K. (1993). Research Paradigms in Education: Towards a Resolution. Journal of Indian Education $19(2), 1-6$

Institute of Development Studies, (2006). A review of IDS research on the environment. University of Sussex. Retrieved from www.ids.ac.uk/ids/KNOTS.

Kamunge Report (1988). Report on the presidential working party on education and manpower training for the next decade and beyond. Nairobi, Government printers.

Kipkoech, L. C., \& Kyalo, W. B. (2010). Management challenges facing implementation of free primary education in Kenya: A case of Keiyo District. International Journal of Educational Administration and Policy Studies, 3 (2), 22-27.

Kratli, S., \& Dyer, C. (2009). Mobile pastoralists and education: Strategic options. Education for Nomads Working Paper 1. International Institute for Environment and Development. London. UK.

Lacey, A., \& Luff, D. (2007). Qualitative research analysis. Sheffield, Trent RDSU, National Institute for Health Research.

Manish, J. (1997). Policy considerations for enabling open learning communities. Last

ICDEjain.html Checked on September 2008 from http://www.unesco.org/education/educprog/lwf/doc/icde/

Marshall, M. N. (1996). Sampling for qualitative research. Great Britain. Oxford U n i v e r s i t y Press, Vol. 13, No. 6. Lastly checked on $23^{\text {rd }}$ May, 2010 at http://spa.hust.edu.cn/2008/ uploadfile/2009-9/20090916221539453.pdf.

Markakis, J. (1999). Pastoralists and politicians in Kenya: In the Review of African Political Economy, Vol. 26, No. 80, Minority Rights Group International. Retrieved August 20, 2008 from@www.minorityrights.org.

Mason, M. (2010). Sample size and saturation in $\mathrm{PhD}$ studies using qualitative interviews: Qualitative Social Research, 11 (3), Art. 8. Retrieved from http://www.qualitative-research.net.

Merriam, S. B. (1998). Qualitative research and case study application in education ( $2^{\text {nd }}$ Ed.). San Francisco: Jossey- Bass Publishers.

Ministry of Education (MOE), Kenya (2009). EMIS statistics for 2003- 2007. Lastly checked on $10^{\text {th }}$ April, 2010 at http://www.education.go.ke/Documents.aspx?docID=832.

Mohamoud, A. (1993). Strategies of nomadic education delivery: State of the art review. Unicef, Somalia.

Mugenda, O. M., \& Mugenda, A. G. (1999). Research methods: Quantitative and qualitative approaches. Nairobi, African Centre for Technology Studies (ACTS) Press.

Ominde Commission. (1964). The Kenya Education Commission Report. Government Printers - Nairobi, Kenya. 
Oreglia, E. (2008). Ethnographic techniques for experience design. UC Berkeley School of Information. Retrieved from http://courses.ischool.berkeley.edu/i290-1/f08/lectures/ISSD-20080929.pdf.

Otive, I. (2006). "The State Of Education in Nigeria: A Keynote Address, Civil Society Action Coalition on Education for All (CSACEFA)". Abuja, Action Aid International.

Roy, C., \& Edwina, P. (2005). The education of nomadic peoples in East Africa: Review of relevant literature (Djibouti, Eritrea, Ethiopia, Kenya, Tanzania, Uganda). IIEP/ African Development Bank 2005, 138 p.

Sandelowski, M. (1995). Sample size in qualitative research. Research in Nursing and Health, 18 (2), 179-83. University of North Carolina at Chapel Hill. Retrieved from http://www.ehow.com/how_ 7571468_determine-appropriate-sample-size.html\#ixzz1SemTCDrC.

Sheila, A. (2006). EFA for pastoralists in North Sudan: A Mobile Multigrade Model of Schooling. In Education for All and Multigrade Teaching: Challenges and opportunities", pp. 193-211, Springer: Dordrecht.

Trochim, W. M. (2006). The research methods knowledge base (2nd ed.). Retrieved from http://www. socialresearchmethods.net/kb/qualval.htm.

Wadi, D. H. (1995). Education policy-planning process: An applied framework. International Institute of Educational Planning. Paris, UNESCO. Retrieved on $22^{\text {nd }}$ May, 2010 from http://www.unesco. org/education/pdf/11_200.pdf.

World Bank (2005). Africa Strategy Paper. IBRD, Washington, DC.

Advised by Edward Tanui, Narok University College, Kenya

Received: February 20, 2012

Accepted: March 06, 2012

\begin{tabular}{|ll|}
\hline David T. K. Serem & Doctor of Philosophy, Educational Administration, Principal, Narok University \\
& College, P.O Box 861-20500, Narok, Kenya. \\
& E-mail: tdkserem@yahoo.com \\
& Website: www.narokuniversity.ac.ke \\
\hline Richard K. Ronoh & Masters in Educational Administration \& Doctor of Philosophy, Educational \\
& Administration (graduation, December, 2011); Lecturer, Narok University Col- \\
& lege, P.O Box 861-20500, Narok, Kenya. \\
& E-mail: ronohrichard@gmail.com \\
& Website: www.narokuniversity.ac.ke \\
\hline
\end{tabular}

